\title{
Proposições de organização curricular na educação de jovens e adultos
}

${ }^{1}$ Doutorando em Educação pela Universidade de São

Paulo, coordenador da Unidade EjA da Ação Educativa

E-mail:_roberto.catelli@ acaoeducativa.org

${ }^{2}$ Mestre em Antropologia Social pela Universidade de São Paulo e assessora da Unidade EJA da Ação Educativa

E-mail: Michele.escoura@ acaoeducativa.org

${ }^{3}$ Socióloga e assessora da Unidade EJA da Ação Educativa

E-mail: edneia.goncalves@ acaoeducativa.org

${ }^{4}$ Doutorando em Letras e assessor da Unidade EJA da Ação Educativa

${ }^{5}$ Graduando em Letras pela Universidade de São Paulo e estagiário da Unidade EJA da Ação Educativa

${ }^{6}$ Mestrando em Educação pela Universidade de São Paulo e assessor da Unidade EJA da Ação Educativa
Roberto Catelli Junior $^{1}$ Michele Escoura ${ }^{2}$ Edneia Gonçalves ${ }^{3}$ Luiz Henrique Magnani ${ }^{4}$ Leonardo Luiz de Matos ${ }^{5}$ Luis Felipe Soares Serrao ${ }^{6}$

Resumo: 0 presente artigo tem como objetivo refletir sobre o modo como são pensadas e efetivadas as políticas públicas para educação de jovens e adultos no Brasil. Concentra-se em analisar a atual conjuntura de EJA de modo a questionar a funcionalidade de apenas um modelo de currículo que se impõe a todo o universo da EJA. Práticas pedagógicas com base em uma perspectiva de letramento, transformações no projeto político-pedagógico das escolas e investimentos em políticas públicas para a modalidade são alguns caminhos discutidos para orientar a elaboração de novas propostas curriculares para EJA. Pretende-se, com isso, argumentar a favor de um olhar voltado para propostas que se descolem do modelo convencional de escola e que atentem a fatores sociais, culturais e históricos que constituem os sujeitos da EJA.

Palavras-chave: Educação de jovens e adultos. Letramento. Proposta curricular. Política educacional. 
Grande parte das escolas para jovens e adultos no Brasil funciona como reprodução simplificada do trabalho realizado na escola tradicional, voltada para crianças e adolescentes. Um retrato dessa incoerência é a frequência com que são vistas salas de aula e bibliotecas com carteiras projetadas para crianças pequenas sendo utilizadas por adultos e salas de aula decoradas com cartazes e dizeres relacionados ao público infantil. Entre tais práticas escolares, poucas são aquelas que utilizam abordagens e materiais didáticos e instrumentos de avaliação específicos para a Educação de Jovens e Adultos (EJA). Mas o que leva a crer que as demandas por educação formal sejam as mesmas nesses diferentes contextos?

Jovens e adultos têm dificuldade em conciliar, entre outras coisas, vida profissional, escola e família; muitos pais não têm com quem deixar seus filhos enquanto estão na escola. Há aqueles que desejam estudar, mas falta um meio de transporte adequado que os levem até a escola.

Desde 2007, assiste-se a um processo de constante queda de matrículas na EJA no Brasil: em 2007, havia quase 5 milhões de matriculados, enquanto que, em 2013, eram aproximadamente 3,1 milhões. Tal queda não é um fenômeno simples de ser compreendido, mas é inegável que os currículos escolares não são atrativos a esse público, uma vez que parecem estar em conflito com as demandas e necessidades desses sujeitos.

É sabido, ainda, que os caminhos pelos quais as crianças aprendem não são os mesmos utilizados pelos adultos. Como afirma Marta Kohl de Oliveira:

\footnotetext{
O adulto está inserido no mundo do trabalho e das relações interpessoais de um modo diferente daquele da criança e do adolescente. Traz consigo uma história mais longa (e provavelmente mais complexa) de experiências, conhecimentos acumulados e reflexões sobre o mundo externo, sobre si mesmo e sobre as outras pessoas. Com relação à inserção na aprendizagem, essas peculiaridades da etapa da vida em que se encontra o adulto fazem com que ele traga consigo diferentes habilidades e dificuldades (em relação à criança) $e$, provavelmente, maior capacidade de reflexão sobre o conhecimento e seus próprios processos de aprendizagem (OLIVEIRA, 2001, p. 18).
}

Assim, um primeiro passo fundamental na EJA é romper com as propostas curriculares pensadas para crianças e adolescentes. Isso envolve repensar desde procedimentos de matrícula e formação docente até instalações físicas, de modo a possibilitar que esses sujeitos construam suas próprias trajetórias de educação formal, condizentes com suas demandas e seus contextos.

Vale mencionar que o currículo deve ser uma proposta sintonizada com o mundo vivido, que não pode prescindir dos sujeitos que o colocarão em prática, conforme salienta Macedo, para quem: 
Em geral, o senso comum educacional percebe o currículo como um documento onde se expressa e organiza a formação, ou seja, o arranjo, o desenho organizativo dos conhecimentos, métodos e atividades em disciplinas, matérias ou áreas, competências, etc.; como um artefato burocrático [...]. O currículo se dinamiza na prática educativa como um todo e nela assume feições que o conhecimento e a compreensão do documento por si só não permitem elucidar. O fato é que os professores e educadores em geral, nos seus cenários formativos, atualizam, constroem e dão feição ao currículo, cotidianamente

(MACEDO, 2007, p. 25-26).

Nesse sentido, este artigo pretende, a partir de uma leitura crítica de algumas dimensões da atual situação da EJA no Brasil, argumentar a favor da construção de propostas curriculares e de uma política pública de EJA alinhadas com as especificidades dos contextos desses sujeitos. Isso não significa propor um currículo ideal, mas propor a criação de tantos currículos quantos forem necessários considerando a especificidade e a diversidade presente na educação de jovens e adultos.

A ESCOLA DE EJA HOJE

Ou então do gorro da blusa. Tem vezes que eu estava sentado, eu sento lá atrás, ninguém está na minha frente; para mim, não é nenhuma falta de respeito, mas eles falam que é (jovem estudante, Itabira, 2013).

Para um jovem, que provavelmente teve uma relação traumática com a escola, não soa adequado retornar para um ambiente que o faz recuar no tempo e voltar para uma proposta de educação pensada para crianças e adolescentes. Voltar para a escola não deveria ser um retorno ao que não foi realizado na infância, mas, sim, a continuidade de processos formativos que podem ter caminhos novos a qualquer tempo da vida.

Essa situação não é um caso particular, e não pode ser dissociada da regulamentação atual da modalidade, que, em alguns pontos, limita o desenvolvimento de alternativas ao modelo atual. As Diretrizes Operacionais da Educação de Jovens e Adultos (CNE, 2010), ainda que busquem garantir a qualidade e as condições adequadas para que jovens e adultos possam aprender, restringem e tornam pouco flexíveis as propostas de cursos presenciais de EJA.

Atualmente, o formato de cursos presenciais é o modelo desenvolvido na grande maioria dos estados e municípios do país. Cerca $4 \%$ da demanda

\footnotetext{
Depoimento concedido à equipe da Ação Educativa em projeto de reorganização curricular da educação de jovens e adultos do município.
} 
potencial de EJA2 está atualmente frequentando escolas nesse modelo, e somente pequena parte desses consegue concluir, pois a soma de reprovados e evadidos chega a $50 \%$ em muitos estados e municípios.

Nos anos finais do ensino fundamental, as Diretrizes Operacionais definem a carga horária de 1.600 horas presenciais, enquanto que, no ensino médio, são exigidas pelo menos 1.200 horas presenciais. No caso da formação técnica integrada ao ensino médio, devem ser destinadas 1.200 horas para a educação geral somadas à carga horária mínima para a respectiva habilitação profissional, o que, em geral, eleva esse total, na maior parte dos casos, para 2.400 horas presenciais ${ }^{3}$. Nas redes públicas de ensino, costumam ser definidas para o ensino fundamental quatro etapas com 400 horas cada uma, distribuídas em cem dias letivos com quatro horas-aula cada um. 0 mesmo ocorre com o ensino médio, organizado em três semestres, com 400 horas cada um. No caso do ensino técnico integrado ao ensino médio, pode-se ter até seis semestres de 400 horas cada um.

Na prática, isso significa que o estudante deve frequentar a escola todos os dias da semana, com horários que, apesar de variáveis, tendem a ocupar o período compreendido das $18 \mathrm{~h}$ às $23 \mathrm{~h}$. Ainda que existam algumas experiências diurnas, não costuma haver espaço físico para uma EJA nesse período, dado que, na maior parte das redes, as escolas são utilizadas para atender crianças e adolescentes, impedindo que a EJA funcione nesse período. Contudo, não é de se ignorar a necessidade de cursos diurnos de EJA, tendo em vista que 15 milhões de pessoas trabalham à noite no Brasil, iniciando sua jornada a partir das $22 \mathrm{~h}^{4}$. Além disso, outros milhões de brasileiros não têm como conciliar trabalho, escola e vida familiar com jornada escolar tão extensa. Segundo o Censo Demográfico de 2010 do IBGE, 28,1\% da população economicamente ativa trabalhava 45 horas ou mais por semana.

2 Em 2011 tínhamos 2,6 milhões de matrículas no ensino fundamental na EJA diante de uma demanda potencial de cerca de 65 milhões de brasileiros com 15 anos ou mais que não concluíram o ensino fundamental. Isso significa que apenas 4,1\% desse público estava em uma escola de EJA. Conforme o Censo, em 2010, 6,9 milhões de pessoas - 10,6\% da demanda potencial - estavam matriculadas em uma escola de ensino fundamental para crianças e adolescentes. Chama a atenção o fato de que 3,2 milhões destas eram pessoas com 29 anos ou mais.

3 Nas chamadas séries iniciais, que equivalem ao ensino fundamental I, incluindo aí o processo de alfabetização, não há qualquer padrão estabelecido nas Diretrizes Operacionais. Podem funcionar cursos presenciais em qualquer formato e duração, desde que as redes de ensino estabeleçam programa e avaliação específicos.

4 O total de trabalhadores que trabalham no período noturno foi calculado pelo Instituto do Sono com base em dados do Ministério do Trabalho. Não há uma coleta e divulgação mais sistemática desse dado pelos institutos de pesquisa. 
No formato semipresencial, no qual não é preciso frequentar a escola todos os dias, os estudantes alternam momentos presenciais com momentos de estudo em casa ou a distância, sempre mantendo a avaliação no processo, como determinam as Diretrizes Operacionais. Alguns estados brasileiros se apropriam desse modelo de maneiras diversas, em que variam o tempo de presença na escola e o modo de organizar o atendimento (individual, em grupo ou por meio de plantões e oficinas) e o espaço escolar, podendo estar a escola aberta até em três períodos.

Há um risco, nesse formato, de se transformar a escola em um plantão de dúvidas e um local de realização de exames, privilegiando um perfil mais autodidata de estudantes. Isso ocorre quando os governos tomam essa estratégia como forma de barateamento da educação de jovens e adultos. Em outros casos, são desenvolvidos trabalhos em que o objetivo, de fato, é criar uma escola apropriada às demandas da educação de jovens e adultos. Esta é uma forma de organizar a EJA que torna viável a frequência e permanência do aluno, uma vez é muito difícil para grande parte dos jovens e adultos em seus contextos cotidianos estar 20 horas semanais na escola.

Um outro modelo de atendimento estipulado pela legislação educacional são os exames de equivalência de escolaridade, os antigos exames supletivos, que muitas vezes são apoiados por cursos preparatórios que prescindem de frequência escolar. Essa forma de organização é a mais flexível, pois não depende de qualquer carga horária ou formato definido pela legislação. Tratase de criar programas de curso adaptados a cada realidade definindo um currículo próprio5. No limite, esse modelo suscita as mesmas preocupações que o formato de cursos semipresenciais.

Finalizando esse breve panorama da organização da EJA no Brasil, conclui-se que, embora exista uma institucionalidade da modalidade no país, há uma oferta relativamente excludente, tendo em vista que, de um lado, o formato presencial não atende às necessidades de grande parte dos estudantes trabalhadores e, de outro, o formato semipresencial e os exames de

Para obter a certificação, nesses casos, é necessário recorrer aos exames estaduais de EJA. Em vários estados, entretanto, os exames supletivos têm sido substituídos pelos exames nacionais: Encceja para o ensino fundamental e certificação via Enem no ensino médio, que tem sido bastante procurado para esse fim. Em 2013 foram 784 mil inscritos pedindo certificação para o ensino médio. Este número fica bem próximo do número de matrículas na EJA Ensino Médio, que, conforme o censo escolar, foi de 970.979 estudantes em 2013. Outra dificuldade na certificação via Enem é o baixo número de pessoas que alcançam a pontuação para a certificação. Em 2013, apenas 60.320 pessoas puderam obter o certificado nas quatro áreas de conhecimento (7,6\%). 
equivalência restringem os itinerários formativos para aqueles que têm perfil mais autônomo para prosseguir nos estudos.

Por fim, é preciso mencionar ainda que são necessárias condições muito especiais para o desenvolvimento da educação de jovens e adultos, que nem se relacionam apenas com a educação, uma vez que não basta para esse público ter o desejo de estudar. É necessário conciliar vida familiar, trabalho e estudo. Por isso, a formulação de uma política de educação de jovens e adultos precisa ter um caráter intersetorial, resolvendo problemas relacionados a transporte, saúde, trabalho e à família. Quer dizer que para uma mãe estudar é preciso criar uma solução em relação ao cuidado dos filhos, por exemplo. É necessário levar em conta também que a grande maioria dos estudantes da EJA é composta de pessoas com baixa renda, sendo aqueles que precisam ser definidos como parte de uma política de inclusão. Por isso, programas de saúde que possam, por exemplo, oferecer exames oftalmológicos e concessão de óculos são fundamentais.

\section{OS SUJEITOS DA EJA}

Os dados do último Censo Demográfico (IBGE, 2010) mostram que 43\% da população brasileira com 15 anos ou mais de idade ainda não completou o ensino fundamental. Esse cenário permite afirmar que a EJA deveria ser encarada como uma política de Estado prioritária.

Em paralelo, os dados do Censo Escolar (MEC/Inep) mostram significativa redução do número de matrículas na modalidade EJA desde 2007. Se a procura por oportunidades escolares poderia ser maior, é de se questionar as razões pelas quais os números de matrículas na modalidade insistem em cair. Talvez uma das possíveis respostas resida nos entraves impostos pelos currículos escolares existentes.

Diante do que já foi colocado em seções anteriores, repensar o currículo para EJA significa levar em conta os contextos de vida, as experiências e aspirações dos sujeitos que a demandam. Para tanto, é crucial saber quem são e onde estão esses sujeitos, suas experiências e expectativas em relação à escola para delinear propostas efetivas para a modalidade. Embora aqueles mesmos sujeitos que reivindicavam espaço na EJA há décadas muito provavelmente continuem à espera de melhores condições para concluírem o ensino básico, novos sujeitos se somaram ao antigo cenário e transformaram a EJA na mesma velocidade em que a própria sociedade se transformou. 
Um caminho ainda incipiente nessa direção tem sido realizado em dois municípios mineiros ${ }^{6}$. Em primeiro lugar, foi realizada a tarefa de identificar os sujeitos da EJA naquelas cidades para, então, pautar os esforços de reorganização curricular. Os dados encontrados trouxeram um perfil não apenas local, mas muito comum de estudantes jovens e adultos de modo geral. Em 2010, 60\% dos estudantes da EJA do Brasil tinham entre 15 e 29 anos, 38\% tinham entre 15 e 21 anos e apenas 2\%, 60 anos ou mais (CENSO ESCOLAR/ INEP, 2010). Na pesquisa realizada em Itabira (MG), fica evidente a primeira mudança conjuntural das últimas décadas: há mais jovens do que adultos na EJA.

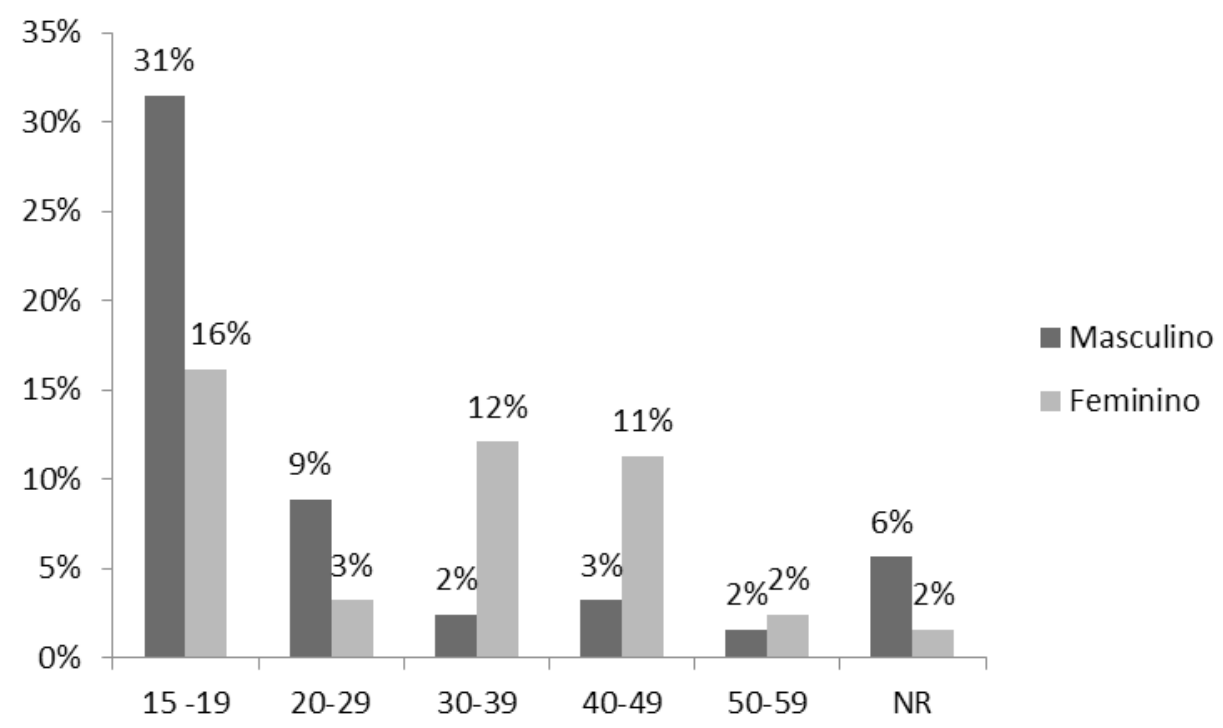

Gráfico 1 - Alunos da EJA/Fundamental em Itabira por sexo e faixa etária, 2013 Fonte: Ação Educativa, 2013.

O fenômeno da "juvenização" da EJA tem sido considerado como um dos principais impulsionadores para repensá-la. O jovem que chega à EJA costuma ser aquele que acumulou uma trajetória de fracassos escolares e se vê na necessidade de elevação de escolaridade imposta pelas novas configurações do mercado de trabalho ou pelo interesse de ingressar nos ensinos técnicoprofissionalizantes e/ou superior. Geralmente, é aquele jovem reprovado ou expulso do sistema regular, que não se adequou ao formato tradicional de ensino e, ao voltar à escola, encontra uma EJA moldada segundo os mesmos padrões da escola regular?.

6 Projeto executado pela Ação Educativa em Itabira e São Gonçalo do Rio Abaixo (MG).

Parte significativa desta nova situação tem a ver com o rebaixamento das idades mínimas para ingresso na modalidade a partir da Lei de Diretrizes e Bases da Educação Nacional, de 1996. 
O perfil desse jovem também tende a ser bastante específico: são eles meninos, pobres e majoritariamente negros. Como destaca Rosimeire Brito sobre esse perfil de meninos com trajetórias de fracassos escolares:

Aos poucos fui percebendo que os estudantes negros, ao escolherem assumir relações de cumplicidade com o modelo hegemônico de masculinidade, eram situados em uma posição de marginalidade [...], tendo em vista seu duplo processo de inferiorização racial: de um lado, ao se associarem à condição de garotos que causavam problemas, acabavam se conformando ao rótulo que identifica as crianças negras como não educáveis (HASENBALG, 1987) e possibilitavam a atualização da profecia autorrealizadora de fracasso escolar, a eles reservada desde os primeiros anos de escolarização. Por outro lado, também se situavam em posição de marginalidade social no âmbito das relações sociais vividas com seus pares masculinos, ou seja, entre os colegas que compartilhavam os mesmos símbolos de gênero do modelo hegemônico, eram descritos pelos pares masculinos como feios e sujos, a ponto de não se verem como portadores de beleza e atratividade sexual (BRITO, 2011, p. 10).

No que se refere ao perfil socioeconômico desses estudantes, é importante considerar a recorrente entrada prematura no mercado de trabalho. Em Itabira (MG), por exemplo, 59\% dos homens e 69\% das mulheres da EJA na cidade começaram a trabalhar antes dos 16 anos de idade e, provavelmente, esse foi um dos motivos que os/as afastaram da escola antes de concluírem o ensino fundamental.

Miguel Arroyo considera essa questão essencial para se pensar o currículo na EJA. Somado ao fato de terem iniciado suas jornadas de trabalho ainda muito jovens, Arroyo destaca o quanto são essas as pessoas que assumem os postos mais precários de trabalho. 0 autor evidencia o quanto o perfil do estudante da EJA está próximo ao perfil do/a jovem à margem dos direitos sociais básicos e, por isso, defende que a modalidade de ensino seja incluída como uma espécie de política de ação afirmativa. Para o autor, a defesa é por:

Currículos que os capacitem para ter mais opções nessas formas de trabalho e para se emancipar da instabilidade a que a sociedade os condena. Conhecimentos e capacidades que fortaleçam como coletivos que os tornem menos vulneráveis nas relações de poder (ARROYO, 2007, p. 10).

Outro ponto de destaque diz respeito às trajetórias femininas. Ao se analisar a evasão escolar a partir da perspectiva de gênero, foi comum encontrar relatos de mulheres que abandonaram os estudos porque tiveram filhas/os. Em Itabira, das mulheres que estão na EJA, 69,2\% são mães, o que dá margem para questionar as condições que elas tiveram para conciliar maternidade e

HASENBALG, Carlos A. Desigualdades sociais e oportunidade educacional: a produção do fracasso. Cadernos de Pesquisa, São Paulo, n. 63, p. 24-29, 1987. 
frequência à escola. Quando se observa a faixa etária das mulheres que estão na EJA na cidade, por exemplo, nota-se que elas são a maioria no grupo de estudantes com idade entre 30 a 59 anos. Muitos são os relatos de mulheres que não tinham como frequentar as aulas noturnas da EJA, pois não dispunham de alternativas para o cuidado de suas crianças enquanto estivessem na escola. Assim, muitas delas só conseguiram retomar os estudos quando suas/seus filhas/os já eram maiores e mais independentes, ou seja, quando elas já estavam na faixa etária posterior aos 30 anos.

Essa questão da dificuldade em conciliar a escola com outras tarefas, como os cuidados com a família, é vivida de modo análogo pelos homens em relação ao seu horário de trabalho. Retomando a indicação de Arroyo sobre o quanto as/os estudantes de EJA são as/os mesmas/os trabalhadoras/es que ocupam os postos mais precários de trabalho, é importante notar como uma rotina escolar rígida e espelhada na escola regular e infantil não condiz com a necessidade de flexibilidade da vida juvenil e adulta: "a maior parte dos jovens e adultos na EJA são vítimas, exatamente, da rigidez dos tempos escolares desde o pré-escolar e, ainda, teimamos que eles se adaptem à mesma rigidez no tempo da EJA" (ARROYO, 2007, p. 13).

Mas se essas jovens mães, trabalhadoras/es e negras/os, são pessoas marcadas por trajetórias escolares de exclusão e de marginalidade e são facilmente reconhecidas nas salas de aulas de EJA hoje, há ainda uma parcela da população invisibilizada até mesmo nos levantamentos estatísticos da modalidade. Pesquisas sobre os cotidianos em escolas têm apontado cada vez mais a dimensão homofóbica do ambiente escolar. Em pesquisa nacional sobre juventudes e sexualidade (ABRAMOWAY, 2004), a Unesco reconhecia o ambiente escolar como espaço marcadamente violento e hostil para pessoas LGBT (Lésbicas, Gays, Bissexuais, Travestis e Transexuais) no Brasil.

De tal cenário de discriminação e violência, um ciclo de abandono escolar se instala e afasta travestis e transexuais das salas de aulas ainda na adolescência. Existe ainda, entretanto, uma grande carência de estudos que analisem o processo de exclusão escolar de pessoas LGBT. Pouca atenção tem-se dado também à presença das pessoas LGBT na EJA, o que se reflete na falta de políticas específicas para esse grupo nesta modalidade. Marcado como espaço de acolhimento de sujeitos com distintas trajetórias de exclusão e marginalização do sistema regular de ensino, a EJA emerge como um espaço privilegiado para ações voltadas à reinserção escolar de pessoas LGBT e, desse modo, seu fortalecimento pode se constituir como política de ação 
afirmativa no combate às discriminações sofridas por elas durante a trajetória escolar regular.

Da diversidade de sujeitos da EJA, é possível identificar como ponto em comum as marcas de discriminação, desigualdade e exclusão que permearam suas vidas e suas relações com a escola. Para que a educação de jovens e adultos se consolide, de fato, como um espaço para a garantia do direito à educação dessa parcela da população é preciso, antes de tudo, reconhecer as necessidades e demandas específicas desses grupos. Nesse sentido, o currículo emerge como campo de intervenção e disputa: seja a disputa pelos sentidos da educação ou pelo interesse desse público de jovens e adultos que permanecem à margem da escola.

Muitos dos sujeitos que chegam à EJA, chegam a ela em decorrência de experiências de exclusão e discriminação que ocorreram no ensino regular e na sociedade. É importante que ao chegarem à EJA encontrem um lugar onde suas histórias, saberes e diferenças tenham espaço e acolhimento e possam contar com o apoio de outras políticas para além da educação que ampliem suas condições de permanência e maior sucesso na educação e na vida (CARREIRA, 2014, p. 1.344).

UMA OUTRA ESCOLA PARA OS SUJEITOS DA EJA

No que se refere especificamente à EJA, o documento final da VI Conferência Internacional de Educação de Adultos (Confintea), realizada em Belém (PA) em 2009, expressa algumas das preocupações que podem nortear a construção de currículos adequados a esses sujeitos.

A aprendizagem e educação de adultos têm como objetivo garantir contextos e processos de aprendizagem que sejam atraentes e sensíveis às necessidades dos adultos como cidadãos ativos. Diz respeito ao desenvolvimento de indivíduos autoconfiantes e autônomos, reconstruindo suas vidas em culturas, sociedades e economias complexas e suscetiveis a rápidas mudanças - no trabalho, na família, na comunidade e na vida social. A necessidade de tentar diferentes tipos de trabalho ao longo da vida, a adaptação a novos contextos em situações de deslocamento ou migração, a importância de iniciativas empreendedoras e a capacidade de manter melhorias na qualidade de vida - essas e outras circunstâncias socioeconômicas requerem aprendizagem continuada ao longo da vida adulta. A aprendizagem e educação de adultos não apenas oferecem competências específicas, mas são também um fator essencial na elevação da autoconfiança, da autoestima e de um sólido sentimento de identidade e de apoio mútuo (CONFINTEA VI, 2009, tópico 5).

Certamente não há um modelo de educação de jovens e adultos que possa ser considerado o melhor. Sistemas fechados e burocratizados tendem ao fracasso ou ao atendimento muito reduzido. Como veremos a seguir, um primeiro pressuposto fundamental é fazer com que, de fato, a EJA esteja incluída nos projetos político-pedagógicos das escolas e, somado a isso, 
perspectivas didáticas focadas nos estudos dos letramentos podem ser um importante caminho de redirecionar a modalidade. Paralelamente, as políticas públicas devem estar orientadas de modo a assegurar autonomia para que as escolas realizem seus trabalhos.

\section{Projeto político-Pedagógico para a EJA}

Para efetivar a escola enquanto espaço privilegiado de diálogo, de acolhimento da diversidade sociocultural e de expressão das transformações locais e globais, é necessário que seu funcionamento seja pautado por um projeto político-pedagógico (PPP). Este deveria se configurar como um processo democrático e intencional de construção da identidade escolar. Sobre esse ponto, Ilma Alencastro Veiga afirma que:

\footnotetext{
O projeto político-pedagógico tem a ver com a organização do trabalho pedagógico em dois níveis: como organização da escola como um todo e como organização da sala de aula, incluindo sua relação com o contexto social imediato, procurando preservar a visão de totalidade. Nesta caminhada será importante ressaltar que o projeto político-pedagógico busca a organização do trabalho da escola na sua globalidade. A principal possibilidade de construção do projeto político-pedagógico passa pela relativa autonomia da escola, de sua capacidade de delinear sua própria identidade. Isto significa resgatar a escola como espaço público, lugar de debate, do diálogo fundado na reflexão coletiva (VEIGA, 2009, p. 14).
}

Da análise de PPP de algumas escolas brasileiras, emerge a permanência da identificação da EJA com uma proposta de educação compensatória. 0 caráter de recuperação do aprendizado não realizado na idade entendida como "certa" reforça o deslocamento do atendimento das demandas formativas dos jovens e adultos do campo do direito para o campo da assistência aos desfavorecidos. A priorização da educação das crianças direciona a organização do ambiente escolar, da rotina e da sua relação com a comunidade e outros espaços de construção de conhecimento, manifestando atenção mínima às especificidades da EJA e ausência de ações/atividades específicas para seu público.

Alguns padrões de abordagem da EJA presentes no PPP são fundamentais na definição do lugar do atendimento de seu público no ambiente escolar. 0 padrão básico é a simples citação como modalidade de ensino atrelada ao atendimento à legislação educacional sem implicação direta na tomada de decisões ou na organização geral da escola.

Destacamos alguns indicadores que contribuem para a reflexão e acolhimento das especificidades da EJA na organização dos tempos e espaços da escola: 
1) a participação dos sujeitos da EJA no processo de elaboração dos PPP; 2) identificação das demandas da população juvenil e adulta local; 3) estratégias para a satisfação das necessidades básicas de aprendizagem de seus estudantes.

Quanto à participação dos sujeitos da EJA no processo de elaboração dos PPP, nota-se que o ideal democrático de reflexão coletiva ainda está distante da realidade. Esse cenário é sintomático: reflete a ausência dos estudantes na tomada de decisão sobre os rumos e responsabilidades nas propostas de desenvolvimento e funcionamento das escolas. De modo geral, a participação dos estudantes e da comunidade tem se restringido às consultas por meio de questionários e reuniões pontuais. As resoluções do PPP, em contraponto, constituem-se a partir de proposições da gestão ao corpo docente e demais profissionais identificados como apoio (administrativos, cozinha, serviços gerais). Esse processo reflete a persistência de um caráter hierárquico nas relações estabelecidas interna e externamente pela escola.

A construção da identidade institucional das escolas necessariamente passa pela identificação do perfil, cultura e necessidades de aprendizagem de sua população. As identidades da EJA, como discutido anteriormente, estão diretamente ligadas às particularidades do universo juvenil e adulto e suas temáticas prioritárias. As necessidades de aprendizagem desse público exigem abordagens pedagógicas específicas: engajadas e compatíveis também com a valorização dos saberes construídos fora do ambiente escolar.

Ao analisar alguns PPP, é possível perceber que ainda quando aparece a ideia de valorização dos conhecimentos prévios dos estudantes da EJA, essa valorização não se traduz em estratégias para colocá-los em articulação com os conhecimentos escolares. Muitas vezes centra-se somente na superação de demandas mínimas de ensino (como, por exemplo, a alfabetização) e não fundadas nas identidades dos sujeitos: no conhecimento da trajetória das pessoas reais e no reconhecimento dos jovens e adultos como produtores de conhecimento e sujeitos de aprendizagem.

Tentar concretizar e apresentar as reflexões de uma escola sob a forma de um documento pode ser interpretado, para além das explicações de suas intenções, como uma maneira de limitar sua prática por meio de um processo de planejamento. Sem negar a possibilidade da existência dessa dimensão, seria restritivo reduzi-lo tão somente a ela, pois, além de os processos de planejamento poderem produzir esquemas ideológicos e de ação específicos, eles também têm valor como propiciadores de transformações e mudanças (GAIRÍN, 1993). 
A organização da rotina e dos espaços da EJA nas escolas também é significativa na elaboração dos PPP. A atenção às escolhas profissionais e familiares dos estudantes, a articulação com agentes e espaços culturais (educação formal e/ou não formal) deveriam repercutir, por exemplo, em transformações da estrutura escolar.

Dentro dessa linha, o PPP se configuraria como um constante diálogo entre local e global no processo de construção da identidade da escola. Vera Masagão Ribeiro indica que o fato de jovens e adultos estarem, por exemplo, inseridos no mundo de trabalho torna necessário focalizar a ação pedagógica no presente, o que obriga a construir um redirecionamento, pois

[...] ao tratar com alunos jovens e adultos, os educadores se veem mais provocados a desvencilhar-se de preceitos forjados na tradição de ensino fundamental propedêutico, segundo os quais a formação geral deve anteceder a formação profissional ou, numa perspectiva ainda mais restritiva, "primeiro se assimila, depois se aplica". A educação de jovens e adultos obriga os educadores a focalizar sua ação pedagógica no presente,

enfrentando de forma mais radical a problemática envolvida na combinação entre formação geral e profissional, entre teoria e prática, universalismo e contextualização etc.

(RIBEIRO, 1999, p. 193-194).

A EJA, no presente, tem que levar em conta seus diversos sujeitos. Em especial, precisa refletir sobre o lugar dos jovens e adultos nas suas salas de aulas. Para tanto, o PPP não pode se tornar um documento inflexível, desatento às mudanças históricas que podem alterar características e demandas relacionadas à escola.

\section{O LeTRAMENTO COMO FOCO NA EJA}

A constituição de um currículo de EJA que se sustente do ponto de vista políticopedagógico necessita da articulação com ações formativas e com a elaboração de materiais didáticos específicos. Muitos desses jovens e adultos chegam à escola para aprender formalmente o sistema alfabético de escrita; outros, para consolidar tais conhecimentos; alguns, ainda, para dar continuidade à escolaridade. Todos eles têm conhecimentos diversificados e possuem tal como qualquer adulto inserido em um mundo letrado - capacidade para desenvolver operações mentais bastante elaboradas. Costumam possuir inserção no mundo do trabalho e em práticas culturais diversificadas (lazer, religião, dentre outras), lidando com textos escritos em tais situações.

Ainda assim, considerar válidos os saberes dos educandos não deve acarretar um movimento simplista ou relativista de ignorar as demandas sociais diante 
desse público letrado, mas pouco escolarizado. Para ampliar o escopo de suas possibilidades participativas, inclusive em outras instâncias de atuação, a sociedade contemporânea exige deles comportamentos, pressupostos e habilidades específicas, geralmente relacionadas a contextos prestigiados de uso da língua. Dessa maneira, apropriar-se de modos prestigiados de interpretação e produção de textos correntes em seu entorno sociocultural mais amplo configura-se, muitas vezes, como uma necessidade ou como uma perspectiva de conseguir maior trânsito e respaldo social.

Nessa perspectiva, as práticas de letramento, concebidas como um conjunto de práticas sociais de uso principalmente da leitura e da escrita ${ }^{9}$, associadas aos contextos tecnológicos, ambientais e histórico-culturais em que ocorrem, tornam-se centrais como ponto de partida para repensar o currículo dentro das especificidades da EJA.

De um ponto de vista educacional mais amplo, aliás, tais demandas sequer devem ser vistas como novidades ao se pensar na relação entre educando e sala de aula. Diferentemente, alinham-se com uma percepção da escola - independentemente de seu segmento - como espaço insuficiente para capitanear ou prescrever os processos educacionais por que seus alunos passam ou devem passar. Em consonância com tal perspectiva - na qual a escola se apresenta em crise ao não conseguir lidar com a presença e a importância dos aprendizados extraescolares (HEATH, 1983; GEE, 2003; GOMES, 2010) - Lemke (s.d.) discorre sobre a inadequação desse espaço institucional quando pensado como local único em que a educação ocorre.

Para o autor, é necessário dissociar educação e escolaridade: aquela envolveria toda uma comunidade e os modos como ela promove a aprendizagem e a compreensão do que é considerado prestigiado em seus limites; a última se limitaria a uma tecnologia particular de algumas comunidades humanas para se fazer educação.

Como desdobramento a esse raciocínio, o autordefende que não se pode esperar que a educação, quando delegada a um pequeno número de especialistas, funcione. Haveria, assim, na concepção do autor, a necessidade de que "cada membro da sociedade, velhos e jovens" assumam "a responsabilidade por educar os outros". Assim, do ponto de vista educacional, Lemke parece

9 Vale ainda mencionar que, em uma sociedade letrada, mesmo as práticas orais ou com outras formas não verbais de se expressar tendem a ser atravessadas por um discurso constituído na modalidade escrita. Isso fica mais evidenciado, por exemplo, em casos que envolvem certos gêneros orais formais, como intervir oralmente em uma reunião de moradores do bairro ou ouvir poemas declamados. 
encarar a escola como apenas um recorte dos contextos sociais nos quais o educando pode efetivamente aprender ou se inserir. Em sua visão, “nenhuma escola, nenhuma sala de aula pode jamais conter o mundo inteiro, ou mesmo qualquer parte sua interessante o bastante" (LEMKE, s.d.).

Em termos gerais, a diferenciação proposta por Lemke (s.d.) interessa no presente texto para se refletir sobre a qualidade política de discursos e práticas que são priorizados em contextos formais de ensino. Nesse sentido, vale também ressaltar o trabalho de Heath (1983) a respeito de letramentos e práticas sociais. Em tal pesquisa, que se tornou bastante influente entre estudiosos do letramento, a autora contrasta padrões e expectativas de ensino próprias de um contexto escolar formal com práticas letradas presentes no cotidiano de duas comunidades subalternas na região da Carolina do Norte (EUA).

Tal estudo traz à tona a riqueza e a complexidade de práticas letradas próprias e significativas no contexto das comunidades. Isso, além da inserção e do domínio dos sujeitos envolvidos em tais práticas. Contudo, mostra que tais, assim que manifestados em sala de aula pelas crianças, geravam conflitos por suas diferenças com as expectativas escolares. Nessas situações, foi percebida uma tendência de os saberes de tais estudantes serem interpretados como ruídos ou desvios ao que era tido por padrão: um modelo específico de letramento, calcado em práticas e conhecimentos prévios naturalizados no cotidiano de classes socialmente privilegiadas. Assim, tais crianças não só tinham suas experiências anteriores desvalorizadas ou ignoradas no processo pedagógico, como também eram solicitadas a aprender práticas que lhe eram distantes. Como resultado, era comum que tivessem menor sucesso escolar em relação àquelas cujas práticas dentro e fora da escola mostravam-se mais alinhadas.

Esse cenário pontual - mas sintomático - põe em foco relações entre práticas escolares e extraescolares. Ou, mais particularmente, entre saberes e letramentos priorizados em sala de aula e a trajetória de sujeitos cujo cotidiano é marcado por práticas diferentes e não valorizadas em tal ambiente. Também chama a atenção para o fato de que aquilo que é ensinado na escola não é algo neutro, mas necessariamente vinculado a práticas e saberes valorizados e naturalizados por grupos sociais específicos. Diante disso, não é difícil concluir que as escolhas que compõem um currículo devem ser pensadas como eminentemente políticas. Por fim, lembra que práticas cotidianas relacionadas à linguagem e à escrita são significativas dentro do contexto em 
que se realizam.

Quando essa discussão mais geral está vinculada às especificidades da EJA, é necessário considerar a emergência de alguns outros desdobramentos. Além da já pontuada relação traumática com a sala de aula que esse educando muitas vezes traz como marca, é de se salientar o fato de que tais sujeitos tendem a estar por mais tempo expostos a aprendizados significativos fora da escola, como, em muitos casos, o universo do trabalho. Assim, ainda que em alguns casos necessitem, porventura, da mediação de outras pessoas para ter acesso a tais textos, também possuem, de modo mais consolidado, domínio em relação a suas possibilidades de agir na sociedade e interagir nos espaços por onde circulam. A esse respeito, é flagrante a situação ilustrada por Kleiman (2005, p. 30-31) em relação a "sindicalistas que redigem cartas de reinvindicação em nome do grupo de trabalhadores que representam, mas precisam, para isso, de secretárias (como escribas), porque não são alfabetizados".

A título de exemplo, a autora apresenta uma carta "ditada por um líder sindical analfabeto à sua secretária alfabetizada, que teve o trabalho de transcrever o texto extremamente coerente e especializado que o líder the 'falou'" (KLEIMAN, 2005, p. 31). Chama a atenção, nesse caso, o conhecimento das estruturas formais que devem compor o gênero em questão, repassadas de modo oral pelo sindicalista em questão ${ }^{10}$. Conforme a própria autora ressalta, "as características do gênero, a estrutura complexa da carta e o vocabulário especializado não constituem problema de produção escrita para esse líder, mas o alfabeto certamente sim" (KLEIMAN, 2005, p. 31).

Uma produção textual como a analisada pela autora ajuda a repensar algumas questões envolvendo escola, letramento e o mundo adulto. Coloca em xeque tanto a falta de diálogo que a escola costuma ter com os saberes prévios dos adultos nela inseridos, como também o forte vínculo e dependência que os currículos de EJA tendem a manter com a escola voltada para crianças e adolescentes. Para muitos jovens e adultos, a inserção no mundo letrado já aconteceu majoritariamente fora da escola, de acordo com suas necessidades e preferências, abrangendo uma gama de gêneros discursivos e de eventos de letramento variada. Se o conhecimento extraescolar do sujeito já não poderia ser ignorado em se tratando de crianças em processo de escolarização, essa questão fica ainda mais salientada em contextos de ensino voltados para

10 Dentre esses elementos, estão o domínio do registro formal da língua, a enumeração de itens como estratégia argumentativa ou mesmo a própria organização textual, na qual fica evidente a presença de introdução, desenvolvimento e conclusão. 
jovens e adultos.

Diante desse quadro, não é difícil concluir alguns pontos. Em primeiro lugar, que as demandas próprias de uma escola voltada para crianças e adolescentes não vão se equivaler àquilo que um público jovem e adulto necessita de um contexto formal de ensino. Além disso, o conhecimento prévio, os interesses particulares do educando e suas práticas letradas cotidianas devem ser tomados como importante ponto de partida em uma EJA comprometida politicamente com seu público. Isso quer dizer, entre outras coisas, que a educação, nesse contexto, não pode querer ser totalizante ou centralizadora das formas de aprender e dos saberes que o sujeito necessita. Em vez disso, deve dialogar com os letramentos trazidos por seus educandos de modo a articulá-los com as demandas sociais próprias de seu contexto e de seu entorno social mais amplo. Tudo isso, por fim, implica assumir o compromisso de garantir as aprendizagens consideradas relevantes para os sujeitos da EJA ao longo dos anos dedicados à educação formal, além de ofertar caminhos para um aprendizado contínuo e significativo - na escola e fora dela.

\section{ARTiculações das políticas PÚBlicas de EJA}

As disputas pelo reconhecimento da EJA enquanto um direito positivado e dotado de efetividade vêm desde meados do século passado, mas, como encontramos em Haddad (2007, p. 197), “[...] esse direito só foi formalizado em lei, como dever de oferta obrigatória pelo Estado brasileiro, a partir da Constituição de 1988, e reafirmado pela Lei de Diretrizes e Bases de 1996". A assunção da educação à condição de um direito social é um processo relativamente recente na história brasileira marcado por avanços em períodos democráticos, sobretudo quando analisado a partir da história da EJA.

O reconhecimento jurídico do direito humano à EJA está posto enquanto direito público subjetivo. Ela é uma modalidade específica da educação básica apoiada na defesa do direito de todos e de todas à educação ao longo da vida e no reconhecimento de pessoas jovens e adultas como sujeitos de conhecimento e de aprendizagem. As lutas e pressões sociais em torno de sua conquista a elevaram à condição de uma das principais vias de construção da plena efetivação da cidadania contemporânea. Esse direito foi salientado por Carlos Roberto Jamil Cury (2002, p. 260), para quem 
O direito à educação parte do reconhecimento de que o saber sistemático é mais do que uma importante herança cultural. Como parte da herança cultural, o cidadão torna-se capaz de se apossar de padrões cognitivos e formativos pelos quais tem maiores possibilidades de participar dos destinos de sua sociedade e colaborar na sua transformação. Ter o domínio de conhecimentos sistemáticos é também um patamar sine qua non a fim de poder alargar o campo e o horizonte desses e de novos conhecimentos.

O acesso à educação é também um meio de abertura que dá ao indivíduo uma chave de autoconstrução e de se reconhecer como capaz de opções. O direito à educação, nesta medida é uma oportunidade de crescimento cidadão, um caminho de opções diferenciadas e uma chave de crescente estima em si.

Contudo, por mais que os textos legais e documentos e retóricas oficiais reconheçam a importância da EJA e ressaltem a necessidade de se responder às especificidades e necessidades das pessoas jovens e adultas para retomar os estudos, os arranjos institucionais atuais da política educacional parecem não propiciar condições objetivas reais e adequadas para que esses/as diferentes sujeitos da EJA definam e busquem suas próprias trajetórias/ itinerários de formação.

Pela reiteração de discursos baseados em argumentos econométricos sobre a questionável baixa relação entre custo-benefício dos gastos com adultos em relação aos investimentos em crianças e adolescentes, as políticas de EJA não emergem enquanto tema prioritário de intervenção pública, inclusive com frágil articulação entre as três diferentes esferas da administração pública. Um significativo sinal desse descompasso é a reiterada queda do número de matrículas na modalidade em todas as redes e regiões do Brasil, mostrando a ineficácia de políticas universais para grupos sociais de condições tão diversas.

Se a LDBEN e a CF/88, a princípio, não se apresentam como grandes obstáculos para uma nova EJA, o mesmo não parece acontecer com as Diretrizes Operacionais (MEC, 2010) que regulam o que devem ser os cursos e exames de EJA, principalmente em exigir cargas horárias extensas, sobretudo para jovens e adultos trabalhadores, além de determinar idades mínimas que fortalecem a concepção de EJA como estratégia de correção de fluxo (ou distorção idade-ano) no ensino convencional.

Outro desafio para fazer avançar uma nova EJA é a equação entre processos efetivamente participativos e democráticos de planejamento, gestão e avaliação das políticas públicas para a modalidade, em que pese a necessidade de se produzir e de se publicizar informações sobre as políticas e programas 
de $E J A^{11}$.

O Censo Escolaré uma das únicas fontes de dadose, mesmo com a reformulação de sua metodologia e forma de coleta a partir de 2007, ainda utiliza concepções pouco úteis em relação à EJA, como evasão e abandono, inadequados para capturar a relação intermitente que jovens e adultos mantêm com a educação básica. Nenhuma iniciativa ou sistema de avaliação fornece informações sobre, por exemplo, os resultados de aprendizagem de estudantes e, logo, não há indicadores e metas para as políticas da modalidade, como o Ideb ${ }^{12} \mathrm{e}$ o PAR/PDE ${ }^{13}$. No caso do Programa Brasil Alfabetizado (PBA), principal ação de alfabetização de jovens e adultos no Brasil, que está há mais de uma década em execução pelo governo federal, houve esforços para construir um sistema de monitoramento, mas que dificilmente está atualizado e em funcionamento, e para produzir estudos e pesquisas avaliativas (inclusive de aprendizagem), mas seus relatórios não são dados abertos ao público ${ }^{14}$.

A (re)formulação da CNAEJA e a criação da atual Secadi/MEC ${ }^{15}$ foram pontos positivos no sentido de fortalecer a institucionalidade das políticas de EJA na agenda federal e, logo, nos estados e municípios. Enquanto espaço de articulação e proposição de políticas focadas nas diversidades, a Secadi/MEC atuou decisivamente na criação da Agenda Territorial de Desenvolvimento Integrado de Alfabetização e Educação de Jovens e Adultos, no ano de 2007,

${ }_{11}$ Talvez sintoma dessa histórica falta de dados recente, Haddad et al. (2002), em estudo sobre o estado do conhecimento da produção acadêmica discente dos programas nacionais de pós-graduação stricto sensu em Educação, afirmaram que as conclusões dos trabalhos analisados têm baixo grau de generalização por consistirem, em sua maioria, em estudos de caso que utilizam abordagens qualitativas de pesquisa.

12 O Índice de Desenvolvimento da Educação Básica (Ideb) é calculado a partir das taxas de aprovação, obtidos pelo Censo Escolar, e das médias de desempenho na Prova Brasil e no Saeb. Nenhum desses componentes leva em consideração os/as estudantes de EJA. O Plano de Desenvolvimento da Educação prevê que estados e municípios adiram ao Plano de Metas do Compromisso Todos pela Educação e, como instrumento de planejamento, formulem seu respectivo Plano de Ações Articuladas (PAR). No campo das políticas de EJA, exige-se que municípios e estados mantenham programa de alfabetização de adultos.

14 Um dos poucos documentos públicos sobre o PBA é o relatório da auditoria do PBA realizado pelo Tribunal de Contas da União (TCU), que apontou, por exemplo, a desarticulação entre ações estaduais e municipais, incorrendo muitas vezes na sobreposição de iniciativas, e a descontinuidade dos estudos dos/as egressos/as do programa.

15 A atual Comissão Nacional de Alfabetização e Educação de Jovens e Adultos foi criada em 2003 como espaço de apoio e consulta da Secretaria Extraordinária de Erradicação do Analfabetismo (Seea), do MEC. Hoje ela está ligada diretamente à Secretaria de Educação Continuada, Alfabetização, Diversidade e Inclusão (Secadi), do MEC. 
cujo principal objetivo é congregar as três esferas da administração pública e sociedade civil em prol de uma agenda articulada e intersetorial para a EJA. No entanto, as trocas de gestões federais e estaduais, além da negativa de alguns estados em participar da política, fez com que a Agenda perdesse sua importância estratégica nos últimos anos ${ }^{16}$.

Um dos principais obstáculos a ser superado é a necessidade de fixação de padrões mínimos de qualidade da educação básica e, logo, dos insumos básicos necessários para alcançá-los mediante financiamento adequado, de modo a subsidiar ações apropriadas para superação das desigualdades educacionais, algo que a atual lógica de distribuição de recursos não é capaz de solucionar ${ }^{17}$. A inclusão das matrículas de EJA no Fundeb ${ }^{18}$ foi um passo importante, porém insuficiente, para o fortalecimento e a institucionalização das políticas de EJA, uma vez que não carrega em si o princípio da relação custo aluno- qualidade. Em levantamento de 2008, a Campanha Nacional pelo Direito à Educação (2010) apontou que o custo aluno-qualidade inicial era significativamente maior que os valores praticados pelo Fundeb, situação que influencia diretamente a capacidade institucional de superar desigualdades educacionais.

\section{CONSIDERAÇÕES FINAIS}

Retomando a proposição inicial, reafirma-se que não é possível ter como ponto de partida da EJA os mesmos percursos didáticos nem os mesmos modelos de organização de escola utilizados para crianças e adolescentes. Não se trata de refazer o percurso formativo não realizado na infância, mas sim levar em conta as experiências de vida desses sujeitos inseridos no mundo social. É

16 Moehlecke (2009) ressaltou como limites da então Secad/MEC reduzido poder para traduzir o diálogo junto a movimentos sociais em políticas do MEC, para os sistemas educacionais e para as outras estruturas do governo, fazendo com que seja vista e entendida como instância de amortecimento de conflitos.

17 Os artigos 206 e 211 da Constituição Federal apresentam o conceito de padrão mínimo de qualidade, reforçados na LDBEN em seus artigos 3 e 4.

18 Criado pela Emenda Constitucional no 53 de 2007, o Fundo de Manutenção e Desenvolvimento da Educação Básica substituiu o antigo Fundef (Fundo de Manutenção e Desenvolvimento do Ensino Fundamental e de Valorização do Magistério, criado em 1997 pela Emenda Constitucional no 14). Somente a partir de intenso trabalho de pressão e articulação política da sociedade civil organizada, o Fundeb passou a incluir progressivamente as matrículas em EJA a partir de 2007, englobando sua totalidade a partir de 2009, para fins de cálculo da distribuição dos recursos para a educação. Contudo, a legislação determina que as matrículas da modalidade devem representar, no máximo, $15 \%$ do total do fundo e que o valor para matrículas na EJA é $80 \%$ do valor estimado para matrícula de crianças e adolescentes. 

ressignificados em sala de aula.

No que se refere aos espaços e tempos escolares, faz-se necessário pensar em formatos flexíveis de escola, adequados ao ritmo de vida de pessoas inseridas no mundo do trabalho e com demandas próprias da vida familiar. Isso não se limita unicamente aos espaços urbanos. Essa nova EJA pode ocorrer junto a populações ribeirinhas, trabalhadores das florestas, pescadores - contextos nos quais o modelo de escola presencial, com aulas todos os dias e horários pouco flexíveis, se torna muitas vezes inviável.

É preciso encontrar soluções viáveis para conciliar, por exemplo, trabalho e estudos, pois o modelo atual de escola mostra sinais de incompatibilidade com as condições de vida de parcela significativa de jovens e adultos no Brasil. Nesse sentido, seria interessante propiciar condições para que trabalhadores tenham algum tipo de benefício para voltar aos estudos - como, por exemplo, redução da jornada de trabalho. Afinal, é preciso criar condições objetivas para que a redução do analfabetismo e a conclusão da educação básica sejam, de fato, tomadas como políticas de Estado. De outro modo, o que se faz é apenas pressionar os diferentes sujeitos para que eles, individualmente, por sua conta e risco, criem suas próprias condições.

Na perspectiva de criar novas propostas curriculares para a EJA, talvez seja interessante organizar cursos os quais jovens e adultos possam frequentar conforme as suas possibilidades e tempo disponível, próximo ao formato comum utilizado por instituições de ensino superior. Após cumprir um conjunto de créditos escolares e extraescolares, ele poderia solicitar a certificação de determinada etapa ou ciclo da educação básica, respeitando as temporalidades individuais.

Paralelamente, como apontado nas seções anteriores, é preciso também que o PPP, enquanto instrumento central de organização do cotidiano escolar, atente para as especificidades dos sujeitos da EJA e das comunidades locais como parte constitutiva da identidade da escola. O foco no letramento pode ser também um caminho para o desenvolvimento de perspectivas mais próximas a esse público, valorizando e incluindo suas práticas sociais nos processos de ensino.

Romper com o modelo de escola planejado para crianças e adolescentes exige também definir democraticamente o que deveria ser uma EJA de qualidade e, logo, realizar investimentos estruturais que garantam sua efetivação - como, por exemplo, professores com carreira específica e remuneração digna, instalações físicas adequadas e política de formação continuada. 


\section{Proposals for curricular organization in young and adult education}

Abstract: The present article's purpose is to reflect on how education public policies for young and adults in Brazil are thought of and made effective. It focuses on the analysis of EJA's present conjuncture in order to question the functionality of imposing only one curriculum method to the whole universe of EJA. Pedagogical practices based on a literacy perspective, transformations in schools' political-pedagogical project and investments in public policies for this modality are some of the ways discussed in order to guide formulation of new curricular proposals for EJA. With this we mean to argue for a view that considers proposals that detach themselves from the conventional model of school and that pay attention to social, cultural, and historical factors that compose EJA's participants.

Keywords: Young and adult education. Literacy. Curricular proposal. Educational policy. 


\section{REFERÊNCIAS}

ABRAMOVAY, Mirian. Juventude e sexualidade. Brasília: UNESCO, 2004.

ÁLVAREZ, Manuel et al. 0 projeto educativo da escola. Porto Alegre: Artmed Editora, 2004. (Coleção Inovação Pedagógica).

ARROYO, Miguel. Balanço da EJA: o que mudou nos modos de vida dos jovensadultos populares. In: REVEJ@ - Revista de Educação de Jovens e Adultos, v. 1, n. 0, p. 1-108, ago. 2007.

BASTOS, Keler Cristina Braga de Freitas; LOBO, Carla Marina Neto das Neves. Educação de jovens e adultos e promoção social: um desafio para os educadores. Disponível em: 〈http://cereja.org.br/arquivos_upload/ kelercristina_carlamarina_eja_promsocial.pdf〉. Acesso em: 4 abr. 2014.

BRITO, Rosimeire dos S. Gênero, raça e fracasso escolar: algumas articulações analíticas. In: CONGRESSO INTERNACIONAL DE EDUCAÇÃO, 3., 2011, Ponta Grossa. Anais... Ponta Grossa, 2011.

CAMPANHA NACIONAL PELO DIREITO À EDUCAÇÃO. Educação pública de qualidade: quanto custa esse direito? São Paulo: Campanha Nacional pelo Direito à Educação, 2010.

CARREIRA, Denise. Gênero e raça nas políticas Federais da EJA. In: Educação de Jovens e Adultos: insumos, processos e resultados (Relatório de Pesquisa Ação Educativa). São Paulo: Ação Educativa, 2014.

CONFERÊNCIA INTERNACIONAL DE EDUCAÇÃO DE ADULTOS, 6., 2009, Belém. Declaração de Evidência. Abordagem a problemas e desafios mundiais educacionais globais. Tópico 5. Belém, 2009.

CONSELHO NACIONAL DE EDUCAÇÃO. Parecer CNE/CEB nㅇ 8/2010, aprovado em 5 de maio de 2010. Estabelece normas para aplicação do inciso IX do artigo 4ํำ da Lei no 9.394/96 (LDB), que trata dos padrões mínimos de qualidade de ensino para a Educação Básica pública. Disponível em: 〈http://portal.mec.gov.br/index.php?option=com_docman\&task=doc_ download\&gid=5368\&|temid〉. Acesso em: 4 abr. 2014.

. Resolução no 3, de 2010. Estabelece as Diretrizes Operacionais para a Educação de Jovens e Adultos nos aspectos relativos à duração dos cursos e idade mínima para ingresso nos cursos de EJA. Disponível em: 
«http://portal.mec.gov.br/index.php?option=com_docman\&task=doc_ download\&gid=5642\&ltemid=>. Acesso em: 9 abr. 2014.

CURY, C. R. J. Direito à educação: direito à igualdade, direito à diferença. Cadernos de Pesquisa, n. 116, p. 242-262, jul. 2002.

GAIRÍN, Joaquín. Planteamientos institucionales em los centros escolares educativos. In: Curso de formación para equipos directivos. Madrid: MEC, 2009.

GEE, J. P. What Video Games Have to Teach Us About Learning and Literacy. Nova York: Palgrave/Macmillan, 2003.

GOMES, L. F. Redes sociais e contracultura: a escola fora da escola. In: SIMPÓSIO HIPERTEXTO E TECNOLOGIAS NA EDUCAÇÃO, 3., 2010. Recife. Anais... Recife, 2010, p. 1-23.

HADDAD, S. A ação dos governos locais na educação de jovens e adultos. Revista Brasileira de Educação, Rio de Janeiro, v. 12, n. 35, p. 197-211, maio/ ago. 2007.

. (Org.). Educação de jovens e adultos no Brasil (1986-1998). Brasília: Inep/Ministério da Educação, 2002.

HEATH, S. B. Ways With Words. Cambridge: CUP, 1983.

IBGE. Censo 2010: resultados. Disponível em http://censo2010.ibge.gov.br/ resultados. Acesso em 5 maio 2014.

KLEIMAN, Angela B. Preciso “ensinar” o letramento? Não basta ensinar a ler e escrever? Campinas: Cefiel-Unicamp; MEC, 2005. 60 p.

LEMKE, J. Re-engineering Education in America. s.d. Disponível em <http:// www.jaylemke.com/storage/Reengineering\%20Education.pdf / $>$. Acesso em: 4 abr. 2014.

MACEDO, Roberto Sidnei. Currículo: campo, conceito e pesquisa. Petrópolis: Vozes, 2007.

MEC. Compromisso Todos pela Educação. Disponível em: 〈http://portal.mec. gov.br/arquivos/pdf/diretrizes_compromisso.pdf〉. Acesso em: 4 abr. 2014.

MEC. Índice de Desenvolvimento da Educação Básica - Ideb. Nota técnica. Disponível em: 〈http://download.inep.gov.br/educacao_basica/portal_ 
ideb/o_que_e_o_ideb/Nota_Tecnica_n1_concepcaolDEB.pdf .. Acesso em: 4 abr. 2014.

MEC. Orientações para elaboração do Plano de Ações Articuladas (PAR) dos Estados e Distrito Federal (2010/2014). Disponível em: «file://D:/Perfil_Luis/ Desktop/manualelaboracao_par_estadual_1114.pdf〉. Acesso em: 4 abr. 2014.

MOEHLECKE, Sabrine. As políticas de diversidade na educação do governo Lula. Cadernos de Pesquisa, São Paulo: Fundação Carlos Chagas, v. 39, n. 137, p. 461-487, maio/ago. 2009.

OLIVEIRA, Marta Kohl de. Jovens e adultos como sujeitos de conhecimento e aprendizagem. In: RIBEIRO, Vera Masagão (Org.). Educação de jovens e adultos: novos leitores, novas leituras. Campinas: Mercado de Letras, 2001.

RIBEIRO, Vera Masagão. A formação de educadores e a constituição da educação de jovens e adultos como campo pedagógico. Educação \& Sociedade, Campinas, v. 20, n. 68, p. 184-201, dez. 1999.

TRIBUNAL DE CONTAS DA UNIÃO. Disponível em: «http://portal2. tcu.gov.br/portal/page/portal/TCU/comunidades/programas_ governo/areas_atuacao/educacao/3\%20monitoramento\%20da\%20 alfabetiza\%C3\%A7\%C3\%A30\%20solidaria.pdf〉. Acesso em: 9 abr. 2014.

VEIGA, Ilma Passo Alencastro. Projeto político-pedagógico da escola: uma construção possível. São Paulo: Papirus, 2009.

RECEBIDO: Março de 2014.

APROVADO: Abril de 2014. 